\title{
Author Correction: The emergence and evolution of Earth System Science
}

Will Steffen (1), Katherine Richardson, Johan Rockström, Hans Joachim Schellnhuber, Opha Pauline Dube, Sébastien Dutreuil, Timothy M. Lenton and Jane Lubchenco

Nature Reviews Earth \& Environment (2020) https://doi.org/10.1038/s43017-019-0005-6 Published online 13 January 2020

The originally published article omitted funding support of JR by the European Research Council under the European Union's Horizon 2020 research and innovation programme (Earth Resilience in the Anthropocene, grant no. ERC-2016-ADG 743080). This omission has been corrected in the HTML and PDF versions of the manuscript.

https://doi.org/10.1038/s43017-020-0100-8 I Published online 3 September 2020

(C) Springer Nature Limited 2020 